\title{
PERCEPÇÕES DE PSICÓLOGAS FRENTE ÀS CRENÇAS RELIGIOSAS DE PESSOAS HOSPITALIZADAS: ESTUDO FENOMENOLÓGICO
}

\author{
Psychologists' perceptions front the religious beliefs of hospitalized people: a \\ phenomenological study
}

Percepciones de psicólogas sobre las creencias religiosas de personas hospitalizadas:

estudio fenomenológico

Letícia Silva de Souza

Paulo Coelho Castelo Branco

Andréa Batista de Andrade Castelo Branco

Universidade Federal da Bahia

\begin{abstract}
RESUMO
Objetivamos compreender como quatro psicólogas residentes percebem e realizam intervenções frente às crenças religiosas de pacientes e acompanhantes atendidos em um hospital geral. Os dados foram coletados por meio de entrevista semiestruturada e analisados sob uma perspectiva fenomenológica empírica. Listamos e discutimos os seguintes eixos de significação: a crença religiosa como experiência constitutiva e fator de significação; a crença religiosa como um modo de bloqueio de contato; o lugar da escuta e da sustentação da relação terapêutica ante a crença religiosa do outro. As psicólogas residentes percebem que a crença religiosa amplia ou reduz a vivência do paciente e acompanhante diante do adoecimento, hospitalização e tratamento, para que eles possam ressignificar, adentrar, evitar ou se desimplicar do seu processo de saúde-doença-cuidado.
\end{abstract}

Palavras-chave: Psicologia da Saúde; Psicologia Fenomenológica; Psicologia Hospitalar; Religião; Religião e Saúde.

\begin{abstract}
We aim to understand how four resident psychologists perceive and perform interventions regarding the religious beliefs of patients and companions seen in a general hospital. Data were collected through semi-structured interviews, and were analysis in an empirical phenomenological perspective. We list and discuss the following axes of meaning: religious belief as constitutive experience and a factor of signification; religious belief as a way of blocking contact; place of listening and sustaining therapeutic relationship front the religious belief of the other. Resident psychologists have reported that religious belief expand or reduces the patient's and companion's experience face of sickness, hospitalization and treatment, so that they can re-signify, step in, avoid or disengage from their health-illness-care process.
\end{abstract}

Keywords: Health Psychology; Phenomenological Psychology; Hospital Psychology; Religion; Religion and Heath.

Rev. Nufen: Phenom. Interd. | Belém, 11(1), 71-85, jan. - abr., 2019. 


\section{RESUMEN}

Objetivamos comprender cómo cuatro psicólogas residentes perciben y realizan intervenciones sobre las creencias religiosas de pacientes y acompañantes atendidos en un hospital general. Los datos fueron recolectados desde entrevista semiestructurada y analizados por una perspectiva fenomenológica empírica. Listamos y discutimos los siguientes ejes de significación: la creencia religiosa como experiencia constitutiva y factor de significación; la creencia religiosa como un modo de bloqueo de contacto; el lugar de la escucha y sustentación de la relación terapéutica ante la creencia religiosa del otro. Las psicólogas residentes perciben que la creencia religiosa amplía o reduce la vivencia del paciente y acompañante ante la enfermedad, hospitalización y tratamiento, para que ellos puedan resinificar, adentrar, evitar o desplazarse de su proceso de saludenfermedad-cuidado.

Palabras clave: Psicología de la Salud; Psicología Fenomenológica; Psicología Hospitalaria; Religión; Religión y Salud Mental.

\section{INTRODUÇÃO}

Há tempos o fenômeno religioso se tornou um objeto de estudo e reflexão da Psicologia, em interface com os outros campos, como a Filosofia, a Sociologia, a Teologia e a Saúde. Tal diversidade acontece em razão das múltiplas dimensões que compõe esse fenômeno (Amatuzzi, 2015). Nesse sentido, no que concerne às pesquisas psicológicas e fenomenológicas, a investigação do fenômeno religioso versa o estudo da pessoa sobre as suas vivências e percepções para entender como ele se situa em sua vida, sua concepção de mundo e funcionamento nele (Vergílio \& Holanda, 2011; Freitas \& Holanda, 2014). Diante disso, destaca-se a influência da crença religiosa na vida humana, tendo como premissa a "necessidade de ver a pessoa como um todo ou ver a relação religiosa-psicológica como um todo, como existência global, envolvendo a pessoa e seu meio-religioso, o sentido da vida e a vida em ação, secundada pelo sentimento da fé" (Ribeiro, 2008, p. 199).

Com base nisso, a inter-relação entre Psicologia e Religião, apoiada na perspectiva fenomenológica empírica (Amatuzzi, 2015), circunscreve a possibilidade de compreender o funcionamento humano sob a lógica da crença religiosa relacionada ao contexto de saúde, sobretudo no domínio hospitalar onde, não raro, o fenômeno religioso emerge como uma forma de cuidado e alento para aqueles que sofrem. Existe, pois, um senso de cuidado influenciado pelo paradigma biopsicossocial que indica uma atuação profissional voltada para a (re)construção de significados sobre si, o outro e o mundo, no que tange às dimensões da saúde, qualidade de vida, doença e autonomia (Pereira, Barros \& Augusto, 2011). Ou seja, entende-se que esses aspectos atravessam as formas de cuidar, pois são elementos multidimensionais que não são isolados, interagem entre si e influenciam a questão do cuidado. Por isso, argumenta-se que em situações de vulnerabilidade e dificuldades 
intensas é comum que as pessoas busquem ancorar-se em um sustento ou consolo muitas vezes, encontrado na crença religiosa (Amatuzzi, 2015).

A hospitalização é circunscrita pelo adoecimento que ameaça e limita a vida de um paciente, gerando variados sentimentos de medo, aflição, ansiedade e temor, que também afetam o ente querido que the esteja próximo e o acompanha para dar suporte e manter relações com aqueles que não estão internados. A hospitalização implica um processo que vai desde a internação, passa pelo diagnóstico, e pode chegar até o luto (Neves, Gondim, Soares, Coelho, \& Pinheiro, 2018). O ambiente hospitalar é caracterizado pelas atuações multi e interprofissionais de equipes que atuam para atender as demandas desses pacientes e acompanhantes (geralmente familiares) internados. Esse trabalho demanda do psicólogo prestar atendimentos para essas pessoas, bem como assessorar a equipe que os atendem na elaboração de estratégias e condutas de tratamentos (Tonetto \& Gomes, 2007).

Ao paciente, o profissional de Psicologia deve estar atento às especificidades das demandas que possam emergir, as quais envolvem adoecimento, tratamento, hospitalização e luto. O adoecimento envolve uma dimensão subjetiva do processo da doença tendo em vista a concepção de que ela não se manifesta somente pelos sintomas físicos, havendo ainda outras dimensões que a perpassam, como, por exemplo, as espirituais e sociais (Espinha \& Amatuzzi, 2008). O adoecimento pode gerar alterações da imagem corporal, perdas e limitações que desencadeiam variadas reações emocionais.

Sobre o tratamento, entende-se como o conjunto de intervenções que visam promover a cura ou o bem-estar do paciente. Os procedimentos invasivos, frequentemente, tornam a vivência do tratamento mais dolorosa e ansiogênica. A hospitalização, por sua vez, representa um processo que ocasiona transformações ao longo do período de internação e envolve variáveis como mudança do ambiente físico, despersonalização do indivíduo, estabelecimento de rotinas a critério da equipe, afastamento dos familiares, etc. (Espinha \& Amatuzzi, 2008).

O luto representa um conjunto de reações psicológicas vinculadas às perdas existenciais que variam em relação à intensidade e características pessoais de quem as vive (Martins \& Lima, 2014). Trata-se, pois, de um processo que faz parte da vida humana e, nesse contexto, o psicólogo pode auxiliar a passagem por esse momento custoso.

Assim, no ambiente hospitalar, a experiência religiosa dos usuários e dos profissionais de saúde coexiste com os ditames éticos e protocolos interventivos técnicos que, a despeito de considerarem essa experiência, enfocam outros aspectos existenciais, sobretudo os fisiológicos-orgânicos, para manejar o tratamento. Logo, uma pessoa perpassada e motivada por uma crença religiosa, muitas vezes, depara-se "com a ausência de um espaço na psicologia onde possa considerar essa sua preocupação" (Amatuzzi, 2003, p. 570).

Rev. Nufen: Phenom. Interd. | Belém, 11(1), 71-85, jan. - abr., 2019. 
Diante disso, o profissional de Psicologia pode buscar compreender como as pessoas vão construindo seus significados no que elas sentem e fazem no que tange à dimensão religiosa no contexto hospitalar. Por esta razão, a crença religiosa influencia as percepções e ações dos sujeitos que lá estão, ao passo que o cuidado em saúde, também, é perpassado por esse fenômeno. Destarte, o presente estudo objetiva, segundo uma perspectiva fenomenológica empírica, compreender como psicólogas residentes percebem e realizam intervenções frente às crenças religiosas de pacientes e acompanhantes atendidos por elas em um hospital geral situado no interior da Bahia.

Entende-se o conceito de crença religiosa como uma experiência de re-ligação com uma dimensão transcendente, sagrada e divina (Amatuzzi, 2000), a partir de eventos que são impactantes, marcantes e afetam um posicionamento do sujeito em relação a um sentido último e maior de vida. Essa crença implica uma religiosidade (vivência de religião) que se refere à busca pela compreensão da própria existência humana. Logo, a crença religiosa é permeada pelas variadas concepções e intenções que envolvem a ligação do homem com o transcendente e com a compreensão de sua própria existência na busca e elaboração de significados para si, o outro e o mundo, que são passiveis de contradições, afirmações e transformações, pois partem da experiência humana.

Um dos componentes da crença religiosa é a fé, entendida como um elemento simbólico de proteção contra as adversidades da vida, sendo utilizada de maneira multifuncional de acordo com o objetivo desejado. A fé perpassa uma ligação com algo que é esperado e influencia as tomadas de decisão que mobilizam o ser ante o que se espera (Amatuzzi, 2003).

\section{MÉTODO}

A pesquisa se amparou em um delineamento qualitativo de caráter descritivo. Os sujeitos de pesquisa foram escolhidos intencionalmente (de modo não aleatório), considerando o quadro profissional de estudantes atuantes em um programa de residência multiprofissional de uma universidade situada no interior do Estado da Bahia. Participaram da pesquisa quatro psicólogas residentes convergentes aos critérios de inclusão de estarem matriculadas no programa de residência, ter pelo menos um semestre de incursão na prática hospitalar e declarar anuência após ciência do termo de consentimento e demais informações sobre a pesquisa.

As quatro participantes são mulheres. A participante 1 (P1) está no primeiro ano da residência, a participante 2 (P2) no segundo, a participante 3 (P3) no segundo e a participante 4 (P4) no primeiro. Ressalta-se que elas atuam no hospital geral da região, uma instituição pública que atende múltiplas demandas, como urgência, emergência e cuidado intensivo, oferece espaço para estágios multidisciplinares e projetos de pesquisa e extensão.

Rev. Nufen: Phenom. Interd. | Belém, 11(1), 71-85, jan. - abr., 2019. 
O programa de residência é um espaço formativo que, no ínterim de quatro semestres, intenciona desenvolver nos residentes habilidades e competências para intervenções que contribuam com a melhoria do cuidado em serviços públicos de saúde.

A coleta de dados aconteceu nas dependências da universidade segundo o convite e o comparecimento das residentes em dias/horários pré-definidos. Foram realizadas entrevistas com um roteiro semiestruturado ${ }^{1}$, após a leitura e assinatura de um termo de consentimento livre e esclarecido. Além disso, solicitou-se a permissão para gravar o áudio da entrevista.

A análise dos dados foi baseada na perspectiva fenomenológica empírica de Giorgi e Sousa (2010). Inicialmente, realizou-se a transcrição das entrevistas, procedida de leitura com a intenção de captar o sentido geral das vivências elucidadas, mediante a suspensão de inferências pessoais por parte dos pesquisadores. A segunda etapa consistiu em dividir o texto transcrito em unidades de significação (US), as quais foram definidas (numeradas) por meio das mudanças na fala do sujeito que indicam variações da intencionalidade da consciência sobre o fenômeno em tela e proporcionam uma descrição detalhada das vivências visadas segundo o cotidiano das participantes. Com as US já delimitadas, na terceira etapa, foram analisados os significados psicológicos contidos nas entrevistas. Procurou-se, então, fazer uma conexão entre os significados relevantes e o tema da pesquisa. Este momento

consiste em reexaminar as US de todas as entrevistas transcritas, de modo a identificar os sentidos comuns, verificar suas interdependências e organizá-los conforme uma única descrição em termos psicológicos. Esses elementos comuns e transversais a todos os sujeitos pesquisados convergem para o que Giorgi e Sousa (2010) entendem como a estrutura geral (a essência) do fenômeno estudado (Castelo-Branco, 2014, p.194).

A última etapa do método consistiu em uma sintetização dos significados essenciais que foram captados em todos os dados coletados. Nesta etapa, houve um posicionamento teórico, um direcionamento da intencionalidade dos pesquisadores sobre o

\footnotetext{
${ }^{1} \mathrm{O}$ roteiro foi orientado pelas seguintes perguntas: O que você entende por crença religiosa? Como você percebe a influência da crença religiosa dos pacientes e acompanhantes familiares no enfrentamento da doença? Como você percebe que a crença religiosa afeta o processo de internação no hospital? Como você percebe que a crença religiosa afeta o tratamento dos pacientes e acompanhantes familiares no hospital? Como você percebe que a crença religiosa interfere na elaboração do luto dos pacientes e acompanhantes familiares no hospital? Como você lida com a(s) crença(s) religiosa(s) dos pacientes e acompanhantes familiares no ambiente hospitalar? Você poderia citar algum exemplo em que a crença religiosa de algum paciente e/ou acompanhante familiar influenciou o enfrentamento da doença? Quais estratégias e intervenções você utilizou para manejar esse tipo de demanda?
}

Rev. Nufen: Phenom. Interd. | Belém, 11(1), 71-85, jan. - abr., 2019. 
fenômeno estudado, com vias a interligar o tema da pesquisa aos significados da vivência abordada (Castelo-Branco, 2014).

Salientamos que a realização da pesquisa cumpriu com os requisitos e parâmetros exigidos pelo Conselho Nacional de Saúde (CNS), cujo objetivo é regulamentar a pesquisa em seres humanos. De acordo com a resolução CNS/466/12, o estudo obteve autorização para a sua execução com número de 99194118.5.0000.5556 e número de parecer 3.082.382.

\section{RESULTADOS E DISCUSSÃO}

A partir das US elencadas, organizaram-se três eixos de significação sobre o fenômeno estudado, descritos e discutidos em seguida: a crença religiosa como experiência constitutiva e fator de significação; a crença religiosa como um modo de bloqueio de contato com a situação de hospitalização; o lugar de escuta e sustentação da relação terapêutica ante a crença religiosa do outro.

\section{A crença religiosa como experiência constitutiva e fator de significação}

As regulações feitas pelos conteúdos religiosos atuam como linhas de orientações juntamente com o conjunto de valores éticos e comportamentais que influenciam a percepção do mundo e de seu sentido. A crença religiosa no âmbito hospitalar funciona como uma religação que conecta o paciente/acompanhante com os significados últimos de sua existência, sobretudo, diante do processo de adoecimento (Amatuzzi, 2015). De acordo com Maciel (2004), a crença religiosa é parte do psiquismo humano e funciona como uma válvula reguladora dos comportamentos, atitudes e percepções do homem frente a sua vivência. Desse modo, os conteúdos religiosos, ao se potencializarem, agem como forças que movem o crescimento, sejam por resistência ou por vias mais construtivas.

A atitude de se voltar para isso possibilita chegar a uma compreensão maior da árdua vivência de hospitalização. Desse modo, a religião proporciona um caminho para ampliar sua existência para além da esfera racional (Maciel, 2004), dado que no processo de hospitalização, as explicações técnicas-cientificas nem sempre são suficientes para (re)significar a vivência do paciente/acompanhante. Logo, muitas vezes a crença religiosa do usuário do serviço hospitalar é anterior a toda formulação psicológica e provê uma narrativa originária e aparentemente não justificada no referencial técnico-científico. Toma-se como exemplo o relato da $\mathrm{P} 1$, que diz respeito a sua percepção sobre os pacientes:

A gente não consegue separar assim de uma maneira tão didática (...). Ele [o funcionamento do paciente] acaba acontecendo de maneira muito fluida, muitas

Rev. Nufen: Phenom. Interd. | Belém, 11(1), 71-85, jan. - abr., 2019. 
vezes, sem a pessoa se dar conta, porque aquela crença é algo tão importante, que faz tão parte da identidade, que a pessoa não consegue se separar dela totalmente. Então, o funcionamento é... coeso, fica uma coisa muito integrada (US 05).

Nota-se, diante do exposto, que a crença religiosa está intimamente relacionada a um modo habitual de se relacionar consigo e com o mundo (Amatuzzi, 2008). Com isso, percebe-se a crença religiosa como uma experiência constitutiva da identidade e que antecede e transcende os ditames institucionais, técnicos e científicos que perpassam o contexto hospitalar. Isso provoca nas psicólogas residentes, antes de qualquer intervenção, uma necessidade de compreender como se organiza a relação dos pacientes e acompanhantes com esse fenômeno. No âmbito hospitalar, essa organização da experiência ajuda o paciente/acompanhante a enfrentar o processo de hospitalização. Como exemplo disso, a P1 percebe que em seus casos atendidos: "a crença religiosa, muitas vezes, vai trazer aspectos relacionados à esperança, ao otimismo, à superação, ao milagre. Então, isso vem como um alento, o paciente sentir algum tipo de conforto diante de uma realidade que é muito dura" (US7).

A crença religiosa como modo de enfrentar a hospitalização, atua por vias de ressignificação. De acordo com Amatuzzi (2015), o significado é a representação ou nomeação de um objeto, seja ele concreto ou subjetivo, o qual é construído mediante a relação sujeito-experiência, bem como pela apropriação de significados já constituídos na sociedade. Destarte, conforme o homem experimenta as coisas no mundo, modifica ou acrescenta os significados sobre o que ele depara. O fenômeno religioso, então, é uma via de acesso a uma série de significados que irão oferecer suporte para a elaboração da experiência, conforme P2 elucida no seguinte trecho: "Elas funcionam como um suporte pra essas pessoas. É... ajudam elas a ressignificar o que elas tão vivendo ali. Dar um sentido pro que elas estão vivendo" (US 33).

Percebe-se, portanto, que a crença religiosa pode se manifestar como uma forma de contato que indica uma posição vivida pelo organismo, de modo a organizar suas próprias necessidades (Ribeiro, 2007). A crença religiosa funciona, ainda, como um núcleo experiencial que é incensado pelo processo de hospitalização. Esse núcleo ajuda a (re)organizar a experiência, via significação, e tem um fator nutritivo que possibilita os pacientes/acompanhantes a perpassar esse processo.

Diante de um ambiente em que a existência é colocada à prova, a crença religiosa proporciona uma retroalimentação que ajuda o usuário a elaborar sua experiência para além dos fatores técnico-científicos que explicam o seu sofrimento e direcionam o seu tratamento, implicando, pois, em um cuidado de si (Mota, Trad \& Villas Boas, 2012). A partir disso, as

Rev. Nufen: Phenom. Interd. | Belém, 11(1), 71-85, jan. - abr., 2019. 
psicólogas residentes percebem que essa experiência constitutiva repleta de significações pessoais deve ser considerada em suas práticas de cuidado com o outro.

\section{A crença religiosa como um modo de bloqueio de contato}

Ficou evidente, através dos relatos das entrevistadas, que o contexto hospitalar implica em muitas perdas, mudanças de rotina e impossibilidades de manter o padrão de vida anterior. Por essa razão, os pacientes e acompanhantes atendidos pelas psicólogas residentes utilizam da crença religiosa para evitar contato com a realidade vivida e como artifício para desimplicar-se da situação de adoecimento. Modos de evitar o contato aparecem nos seguintes trechos:

Às vezes, eu pergunto é... o que que ela tá achando... se ela tá melhorando... ou quando é uma situação de quase cuidados paliativos, quando faço perguntas mais diretas sobre o prognóstico e tudo, elas respondem utilizando esse discurso religioso do tipo, 'ah, agora só Deus que sabe' ou 'eu já entreguei nas mãos de Deus' (P2: US 19).

As pessoas utilizam desse discurso religioso para não se implicar, também, nesse processo de enfretamento, como se tivesse delegando essa função para Deus (...) têm coisas que estão sob seu controle e têm coisas que não estão. Têm pacientes que nada está sob o controle deles, tudo tá sob o controle de Deus. Eles não podem fazer nada nesse contexto (P2: US 34).

Os trechos acima denotam que o paciente pode utilizar a crença religiosa para aceitar de forma passiva o seu prognóstico, delegando a Deus a responsabilidade exclusiva sobre sua possível recuperação. Nesse caso, o paciente projeta em Deus sua morte ou sua cura, sem identificar seus recursos internos e capacidades de tomar decisões acerca do seu processo de adoecimento e cuidado. Vale ressaltar que em tal mecanismo de defesa, a projeção, pode se caracterizar como forma de contato saudável ou patológico, visto que, somente quando esta se torna cristalizada, há um bloqueio do contato e se constitui em um comportamento neurótico (Castro \& Souza, 2012). O fato de evitar entrar em contato com a realidade, muitas vezes, faz com que o paciente/familiar se desimplique no processo de adoecimento.

Na circunstância do luto, por exemplo, a crença religiosa viabiliza um meio para lidar com aquele momento difícil, mas que pode prejudicar o enfrentamento da perda. Tomemos o relato de P2:

Sempre era necessário falar sobre morte nos atendimentos mesmo porque eles tavam alí diante da morte iminente (...), mas a família do paciente se esquivava.

Rev. Nufen: Phenom. Interd. | Belém, 11(1), 71-85, jan. - abr., 2019. 
Isso tem a ver com a elaboração do luto também. Era muito mais difícil elaboraro luto depois. Eles se esquivavam até o último momento (US 36).

Segundo Rogers (1959/1977), a experiência é composta por tudo aquilo que perpassa o organismo e potencialmente se torna consciente. A consciência é uma função simbolizadora do organismo. Ao experienciar algo, como a possibilidade de perda de um ente querido, o organismo é afetado por uma presença de mundo. Disto emerge a consciência que se volta (percebe) para o que lhe perpassa (em termos de sentido) e produz uma simbolização (significação). Com efeito, a partir do que se sente diretamente se produz um conteúdo simbólico que irá gerar uma impressão que será marcada em termos de um campo fenomenológico (perceptivo). Logo, a realidade é aquilo que é experimentado e percebido pelo indivíduo no seu campo fenomenológico que irá gerar um conjunto de impressões sobre si, o outro e o mundo. Nesse sentido, a experiência de luto pode ser ameaçadora, pois implica a perda de uma faceta do self. A experiência de perder um filho, por exemplo, implica uma perda da função materna.

Destaca-se que toda reação comportamental acontecerá de acordo com a forma como a pessoa sentiu, percebeu e simbolizou (significou) algum acontecimento que perpassou a sua experiência. Quando a crença religiosa é utilizada para evitar entrar em contato com as emoções da perda e barrar a consciência das necessidades internas e externas, o indivíduo intercepta a simbolização correta de sua experiência.

Rogers (1959/1977), ainda, explana que experiências incoerentes com a organização do self (uma auto-conceituação e simbolização de si) podem ser percebidas como uma ameaça. Como um modo de defesa, é lançada uma sequência de comportamentos em resposta à ameaça, que podem envolver uma: reação de ansiedade; rigidez perceptual, a qual deforma alguns dados da experiência; simbolização incorreta, devido à deformação e omissão de certos dados. Consonante a isso, as psicólogas residentes relatam:

Quando o prognóstico é negativo, eu percebo que as pessoas se apegam um pouco mais na possibilidade de a religião ser algo que dê o que o tratamento da realidade em si não dá conta. Então, assim, o prognóstico é péssimo (...). Às vezes, fica 'nas mãos de Deus', 'o milagre pode acontecer' (P1: US 10).

O tratamento, às vezes, é mais complicado porque demora um certo tempo com casos de câncer nos cuidados paliativos. Então, o tratamento é prolongado e a gente observa essas fases, em alguns momentos a pessoa tá usando a religião como forma de evitação do contato (P3: US 41).

A questão do uso da crença religiosa como uma evitação de contato com a experiência ou um comportamento de esquiva - termo que algumas participantes usaram - é visto como uma barreira que impede o acesso ao paciente/familiar, dificultando o trabalho

Rev. Nufen: Phenom. Interd. | Belém, 11(1), 71-85, jan. - abr., 2019. 
psicológico. Trata-se de um fenômeno de deflexão, visto que o self se desvia do contato direto da possibilidade de perda ou o faz de maneira vaga (Ribeiro, 2007). Para exemplificar, P4 relata:

Em outros momentos ele [o recurso religioso] funciona como uma esquiva de entrar em contato com a situação que geralmente é aversiva e tal. A gente atende casos muito difíceis e aí, às vezes, essa religiosidade ela é utilizada pra evitar entrar em contato com essas experiências que são aversivas. Quando é utilizado como esquiva a gente considera que também tem uma função, se a pessoa tá se esquivando é porque ela não tá dando conta daquilo naquele momento (US 41).

Semelhante a essa fala, a P1 destaca o uso de um possível mecanismo de fixação, uma vez que a pessoa preserva seus valores e crenças religiosas, à despeito da gravidade do quadro clínico, para negar a realidade da dor, da doença ou da morte:

Às vezes a gente não consegue aprofundar algumas questões porque o discurso religioso vem como uma maneira de barrar, porque às vezes é tão doloroso entrar em contato com as próprias questões que se usa o discurso religioso genérico como uma tentativa de barrar o contato (P1: US 19).

As participantes destacam, em suma, que a crença religiosa é uma forma de apegar-se a um consolo para lidar com uma realidade muito difícil. Essa forma de lidar envolve processos relacionados à experiência (sentir o mundo), consciência (se voltar para algo de modo a simbolizar/significar o que se passa na experiência), constituição de uma realidade pessoal (impressões que geram um campo fenomenológico) e reação a isso (comportamento) conforme o que se sente (via emoções), percebe e pensa. Desse percurso, a crença religiosa serve como uma experiência que se assemelha a um escudo que barra o impacto direto do fenômeno da hospitalização.

\section{O lugar de escuta e sustentação da relação terapêutica ante a crença religiosa do outro}

No decorrer das entrevistas, as residentes demonstraram como lidavam com o fenômeno religioso no que concerne à escuta e à relação de ajuda psicológica. Com isso, perceberam-se algumas dificuldades, como, também, estratégias e intervenções utilizadas para o manejo psicológico em situações as quais o fenômeno da crença religiosa emergia como experiência nos pacientes e acompanhantes.

De acordo com Espinha e Amatuzzi (2008), a hospitalização é vista como um processo, porque ela acarreta mudanças ao longo do tempo, sendo uma experiência vivenciada de formas diferentes em cada indivíduo. Assim, "a historicidade deve ser levada em conta quando se busca compreender a vivência da hospitalização" (p. 480), pois os

Rev. Nufen: Phenom. Interd. | Belém, 11(1), 71-85, jan. - abr., 2019. 
sentimentos e significados atribuídos ao sofrimento se modificam de acordo com a passagem no hospital. Por exemplo, no que concerne à comunicação do diagnóstico, a P3 evidencia que o paciente/acompanhante atendido nem sempre vai utilizar a crença religiosa da mesma forma no mesmo processo e que isso lhe requer muita atenção para compreender o momento do outro. Percebe-se a influência de algumas variáveis, no trecho abaixo:

Ah, ao diagnóstico, ao recebimento do diagnóstico, do tempo de internação, é... piora ou melhora do quadro clínico... são coisas que podem estar influenciando ao meu ver. Então, em alguns momentos quando esse quadro tá piorando aí já a gente já percebe uma mudança na forma de enfrentamento do usuário (US 43).

Assim, a crença religiosa não é estática e varia de acordo com a história de vida do sujeito e pela maneira como ele se relaciona com o contexto. Enquanto que, em um dado momento, a crença religiosa gera esperança diante do quadro de diagnóstico/internação, em outro, pode ser vivenciado em termos de um desespero ante a provação que lhe foi imposta pela situação. Essa oscilação deve ser considerada e compreendida na escuta hospitalar. A despeito disso, as entrevistadas relataram que, muitas vezes, o discurso religioso traz algumas dificuldades no manejo terapêutico. A seguir, dois exemplos:

A depender do nível de religiosidade, do nível do discurso, quando muito associado à crença religiosa, às vezes é difícil sustentar uma escuta (P1: US 18).

Eu tenho um pouco de dificuldade de lidar com a crença religiosa, principalmente, nos casos em que a crença é usada como (...) um mecanismo defesa (P3: US 47).

Segundo Savio e Bruscagin (2008), o sucesso terapêutico sobre o manejo clínico com pacientes religiosos está ligado à capacidade de considerá-los como pessoas que possuem hábitos e costumes diferentes, os quais não devem ser julgados. No trabalho psicológico, o profissional deve ser respeitoso com relação aos conteúdos religiosos provindos dos pacientes, embora o seu campo de discernimento não seja o da religião, mas sim do psiquismo.

As dimensões biológica, corporal, psíquica e social são influenciadas pela dimensão espiritual, e essa é desenvolvida a partir das escolhas e dos posicionamentos do homem perante a vida, ou seja, são mutuamente afetados (Amatuzzi, 2008). Exemplifica-se a tentativa do manejo psicológico hospitalar nos casos em que se tentava mostrar ao paciente a sua responsabilidade no processo, segundo se observa no trecho a seguir:

Era muito difícil que ela se implicasse, era um exercício de ficar mostrando para ela que foi uma escolha dela. Que ela entregar nas mãos de Deus significa que escolheu arriscar de ter ou de não ter um bebê (...). Eu ficava falando 'sim, mas

Rev. Nufen: Phenom. Interd. | Belém, 11(1), 71-85, jan. - abr., 2019. 
você entregou pra Deus, tá, mas como é que é entregar pra Deus?' (...). Sempre questionando para pessoa se implicar (P2: US 28).

Dessa feita, como critério psicológico, a experiência religiosa saudável é caracterizada por favorecer a integração e dinamismo da pessoa. Assim, o psicólogo deve auxiliar na ampliação do campo perceptivo, possibilitando que a pessoa perceba se a religião está contribuindo ou prejudicando a sua integração pessoal (Amatuzzi, 2008). Diante disso, o relato da $\mathrm{P} 1$, expresso em seguida, é pertinente ao mostrar o lugar de escuta e relação de ajuda do psicólogo frente ao outro:

Então, foi trabalhando esse processo de lidar com a realidade, de aceitar aquela situação, em paralelo com esse processo de é... ser alguém dentro de uma religião (...) alguém que poderia questionar essa realidade para inclusive aceitá-la. Então... a gente foi fazendo todo um trabalho dele se permitir perguntar a Deus 'por quê?'. A gente foi construindo isso junto. Assim, meu trabalho não foi no sentido religioso, de descobrir qual o seria a resposta de Deus, mas no sentido de manejar a dinâmica psíquica que ele tava apresentando naquele momento (US 25).

Através das entrevistas, destarte, pode-se observar que as psicólogas residentes utilizam estratégias e intervenções convenientes com cada caso. Foi possível perceber que as residentes buscam identificar se a queixa que incomoda o paciente está relacionada à experiência religiosa; se esta é vivida por via de bloqueio ou promoção do seu desenvolvimento integrado à personalidade; e se podem auxiliar na restauração ou ressignificação de uma experiência religiosa mais concernente às suas questões existenciais.

\section{CONSIDERAÇÕES FINAIS}

Este estudo permitiu identificar que a crença religiosa está presente no contexto hospitalar e se manifesta de diferentes formas, perante as peculiaridades e demandas dos pacientes e acompanhantes atendidos pelas psicólogas residentes. Esse fenômeno influencia as vivências de hospitalização no processo saúde-doença-cuidado.

A conjuntura hospitalar é, por si, um acontecimento que promove medo, tristeza, ansiedade e expectativa. Desse modo, a crença religiosa se apresenta como um elemento interpelador da externalização desses afetos. Percebeu-se uma postura de consideração idiossincrática das psicólogas em relação a cada caso atendido, com vias a desenvolver uma estratégia de cuidado diante de cada situação de hospitalização. Nesse sentido, a crença religiosa funciona como uma lente que amplia ou reduz a percepção da pessoa diante de sua hospitalização, fazendo com que nesse contexto ela possa ressignificar, adentrar, evitar ou se desimplicar do seu processo de tratamento. Assim, o manejo psicológico deve ser sensível às condições vivenciadas pelos usuários do serviço, bem como as suas crenças religiosas e

Rev. Nufen: Phenom. Interd. | Belém, 11(1), 71-85, jan. - abr., 2019. 
costumes, de forma a respeitar, reconhecer seus sentimentos e facilitar a integração pessoal no momento vivido.

Com efeito, aponta-se a necessidade de discussões relacionadas ao fenômeno religioso comparecer mais na formação do psicólogo, seja em disciplinas obrigatórias ou optativas relacionadas às temáticas de espiritualidade e religião em cursos de Psicologia. Conquanto ora circunscrita ao contexto hospitalar, considera-se que a crença religiosa faz parte do cotidiano profissional em outros âmbitos, tais como os clínicos, educacionais e organizacionais, por exemplo.

A despeito de a pesquisa ter se limitado às experiências das psicólogas residentes do hospital, como sugestão para futuros estudos, recomendam-se investigações fenomenológicas empíricas sobre o mesmo fenômeno, conforme vivido por outros profissionais de saúde, como médicos e enfermeiros, além compreender diretamente como as crenças religiosas são vividas pelos usuários do serviço hospitalar.

\section{REFERÊNCIAS}

Amatuzzi, M. (2000). O desenvolvimento religioso: uma hipótese psicológica. Estudos de Psicologia (Campinas), 17(1), 15-30. Recuperado em 29 de março de 2019 de, http://www.scielo.br/pdf/estpsi/v17n1/02.pdf. doi: 10.1590/S0103-166X2000000100002

Amatuzzi, M. (2003). Fé e ideologia na compreensão psicológica da pessoa. Psicologia: Reflexão e Crítica, 16(3), 569-575. Recuperado em 29 de março de 2019 de, http://www.scielo.br/pdf/prc/v16n3/v16n3a15.pdf. doi: 10.1590/S010279722003000300015

Amatuzzi, M. M. (2008). Experiência religiosa, psicoterapia e orientação espiritual. In Bruscagin, C., Savio, A., Fontes, F., \& Gomes, D. (Orgs.). Religiosidade e Psicoterapia (pp. 19-36). São Paulo: Roca.

Amatuzzi, M. (2015). Psicologia do desenvolvimento religioso: a religiosidade nas fases da vida. São Paulo: Ideias \& Letras.

Castelo-Branco, P. (2014). Diálogo entre análise de conteúdo e método fenomenológico empírico: percursos históricos e metodológicos. Revista da Abordagem Gestáltica, 20(2), 189-197. Recuperado em 17 de dezembro de 2018, de http://pepsic.bvsalud.org/scielo.php?script=sci_arttext\&pid=S180968672014000200006\&lng=pt\&tlng=pt.

Castro, E., \& Souza, A. (2012). Cuidando da pessoa com câncer: contribuições da GestaltTerapia. Revista IGT na Rede, 9(16), 44-70. Recuperado em 17 de dezembro de 2018, de http://www.igt.psc.br/ojs/ISSN1807-2526

Espinha, T., \& Amatuzzi, M. (2008). O cuidado e as vivências de internação em um hospital geral. Psicologia: Teoria e Pesquisa, 24(4), 477-485. Recuperado em 17 de dezembro de 2018, de http://www.scielo.br/pdf/ptp/v24n4/11.pdf. doi: 10.1590/S010237722008000400011

Rev. Nufen: Phenom. Interd. | Belém, 11(1), 71-85, jan. - abr., 2019. 
Freitas, D., \& Holanda, A. (2014). Conversão religiosa: buscando significados na religião. Gerais: Revista Interinstitucional de Psicologia, 7(1), 93-105. Recuperado em 17 de dezembro de 2018, de http://pepsic.bvsalud.org/scielo.php?script=sci_arttext\&pid=S1983$82202014000100009 \&$ Ing $=p t \&$ tlng $=$ pt.

Giorgi, A., \& Sousa, D. (2010). Método fenomenológico de investigação em Psicologia. Lisboa: Fim de Século.

Maciel, J. (2004). O indisponível e a psicologia. In Holanda, A. (Org.). Psicologia, religiosidade e fenomenologia (pp. 125-146). Campinas, SP: Editora Alínea.

Martins, M., \& Lima, P. (2014). Contribuições da Gestalt-terapia no enfrentamento das perdas e da morte. IGT na Rede, 11(20), 01-39. Recuperado em 17 de dezembro de 2018, de http://pepsic.bvsalud.org/scielo.php?script=sci_arttext\&pid=S1807$25262014000100002 \&$ Ing $=$ pt\&tlng=pt.

Mota, C., Trad, L., \& Villas Boas, M. (2012). O papel da experiência religiosa no enfrentamento de aflições e problemas de saúde. Interface - Comunicação, Saúde, Educação, 16(42), 665-675. Recuperado em 17 de dezembro de 2018, de http://www.scielo.br/pdf/icse/v16n42/v16n42a07.pdf. doi: 10.1590/S141432832012000300007

Neves, L., Gondim, A., Soares, S., Coelho, D., \& Pinheiro, J. (2018). O impacto do processo de hospitalização para o acompanhante familiar do paciente crítico crônico internado em Unidade de Terapia Semi-Intensiva. Escola Anna Nery, 22(2), 01-08. Recuperado em 17 de dezembro de 2018, de http://www.scielo.br/pdf/ean/v22n2/pt_1414-8145-ean2177-9465-EAN-2017-0304.pdf. doi: 10.1590/2177-9465-ean-2017-0304

Pereira, T., Barros, M., \& Augusto, M. (2011). O cuidado em saúde: o paradigma biopsicossocial e a subjetividade em foco. Mental, 9(17), 523-536. Recuperado em 17 dezembro, 2018, de http://pepsic.bvsalud.org/scielo.php?script=sci_arttext\&pid=S167944272011000200002\&lng=pt\&tlng=pt.

Ribeiro, J. (2007). O ciclo do contato: temas básicos na abordagem gestáltica. São Paulo: Summus.

Ribeiro, J. (2008). Reflexões sobre o lugar de uma Psicologia da Religião. Revista da Abordagem Gestáltica, 14(2), 197-204. Recuperado em 17 de dezembro de 2018, de http://pepsic.bvsalud.org/scielo.php?script=sci_arttext\&pid=S1809$68672008000200007 \&$ Ing=pt\&tlng=pt.

Rogers, C. (1977). Teoria e pesquisa. In Rogers, C., \& Kinget, M. (Eds.). Psicoterapia e relações humanas: teoria e prática da terapia não-diretiva (Vol. 1., pp. 143-274., M. Bizzotto, Trad.). Belo Horizonte: Interlivros. (Original publicado em 1959).

Savio, A., \& Bruscagin, C. (2008). A religiosidade na prática clínica: construindo diálogos com o cliente religioso. In Bruscagin, C., Savio, A., Fontes, F., \& Gomes, D. (Orgs.). Religiosidade e Psicoterapia (pp. 19-36). São Paulo: Roca.

Tonetto, A., \& Gomes, W. (2007). Competências e habilidades necessárias à prática psicológica hospitalar. Arquivos Brasileiros de Psicologia, 59(1). Recuperado em 17 de dezembro de 2018, de http://pepsic.bvsalud.org/pdf/arbp/v59n1/v59n1a05.pdf 
Vergílio, S., \& Holanda, A. (2011). Reuniões mediúnicas espíritas: explorando significados e efeitos para seus participantes. Gerais: Revista Interinstitucional de Psicologia, 4(2), 264-275. Recuperado em 17 de dezembro de 2018, de http://pepsic.bvsalud.org/scielo.php?script=sci_arttext\&pid=S1983$82202011000200008 \&$ Ing $=p t \&$ tlng=pt.

\section{NOTA SOBRE OS(AS) AUTORES(AS):}

Letícia Silva de Souza: Graduanda em Psicologia pela Universidade Federal da Bahia, Campus Anísio Teixeira. E-mail: leticiassouz4@gmail.com

Paulo Coelho Castelo Branco: Doutor em Psicologia. Docente e Coordenador do Programa de Pós-Graduação em Psicologia da Saúde da Universidade Federal da Bahia, Campus Anísio Teixeira. Coordenador do Núcleo de Estudos em Psicologia Humanista. Vice-Coordenador do Grupo de Trabalho em História da Psicologia da Associação Nacional de Pesquisa e Pós-Graduação em Psicologia. E-mail: pauloccbranco@gmail.com

Andréa Batista de Andrade Castelo Branco: Doutora em Psicologia pela Pontifícia Universidade Católica de Minas Gerais. Docente e Vice-Coordenadora do Programa de Pós-Graduação em Psicologia da Saúde da Universidade Federal da Bahia, Campus Anísio Teixeira. E-mail: andrea.andradeufba@gmail.com

Recebido em: 28/12/2018. Aprovado em: 04/04/2019. 